\title{
The Effect of Texts-Based Interactional Feedback (TIF) on the Students' EFL Writing
}

\author{
Warsidi \\ Universitas Islam Makassar, South Sulawesi, Indonesia \\ e-mail:warsidi.dty@uim-makassar.ac.id
}

\begin{abstract}
This study is reporting the results of the TIF implementation in a student's EFL writing. It evaluated the student first supervisory paper, the last supervisory paper, and the participant's perception toward the TIF implementation. This is qualitative study with the linguistic features as the scoring frameworks, including lexical sophistication, syntactic complexity, and rhetorical structure. This boundary study is the participant's text findings, discussion, and concluding parts of the paper. The procedures were discussing the student's some supervisory papers after read and corrected by the supervisors. The first and the last paper were compared descriptively. The results of this study revealed that participant's academic writing changed significantly in the rhetorical structure and tended ignoring the other two scoring frameworks. The study also indicated that the student has intermediate level of English and the participant's perception toward the TIF implementation also resulted positively. Therefore, the TIF model is ably applied for teaching EFL academic writing, more specifically in improving the better rhetorical structure.

Keywords: Texts-based Interactional Feedback, TIF, student's EFL writing, linguistic features
\end{abstract}




\section{INTRODUCTION}

More investigation on particular methods, techniques, and approaches to improve writing skill (Bezemer \& Kress 2008; Crossley at al., 2014; Dabbagh, 2017; Dyson, 2013; Hayes, 2012; Okasha \& Hamdi, 2014; Tahmasebi' 2017), particular media to improve writing (Gurbangeldiyewna; \& Hermayawati 2017, Noriega, 2016; Rodliyah,2016), and redefining supervisory feedback in EFL teachers' and supervisors' perception, Mehrpour (2017) has been conducted but still rarely texts-based feedback is investigated for the student's English Foreign Language (EFL) writing in their teaching and learning activities. For examples, a study on writing through the teacher-led collaborative modeling conducted by Tahmasebi (2017) revealed that the results of students' writing performance and self-regulation had significant improvements, while on students' self-regulation had no significant correlation.

For the recent issue, interactional feedback in language learning both in Teaching English as Second Language (TESOL) and Teaching English as Foreign Language (TEFL) had been investigated by some scholars, (Kuure at.al., 1998; Mckay, 2002) including effective supervisory feedback (Mehrpour, 2017), Written Corrective Feedback (Poorebrahim, 2016 and Zarifi, 2017). Because interactional feedback can be applied not only in the classroom activities but also in out of the classroom such as private teaching, language environments, and through long distance learning interaction such as using internet, the application of the interactional feedback needs various concepts for better results as the interactional purposes, for more effective feedback (Mehrpour; 2017). For example, the concept of genre approach to improve the interaction in social life, cultural activities, and personal experience, (Thorne, 2001) has been applied and the aims of the interactional context in the language teaching and learning prefer more to receive the abstract concept of knowledge and skills, Hua at al. (2007; p.1), which it tends to the concept of interaction, Seedhouse (2007). Therefore in the EFL teaching, the interactional context isn't only used for situational purposes, but it also has opportunity to improve the EFL skill, such as in academic writing and other kind studies.

The distinguished feedback purpose has been more upgradable in various learning subject and feedback both written and oral form has become more familiar in linguistic study which allows teachers-supervisors implementing it in the process of teaching-learning activities. The issue on academic writing quality, more particularly in Indonesia where English is in EFL context, and the institutional policy for publishing now can't be neglected, because students and teachers are always encouraged to publish their works in the international reputable journal, for example Kotamjani (2017; p. 2). The demands of good academic writing quality for publishing are more challenging in this era, because some course institutions had applied a policy for qualified academic writing, for example, one of obligatory requirement for achieving Ph.D. course at Universiti Putra Malaysia is publishing two articles in the international reputable journals Kotamjani $(2017$; p. 2). His study investigated the 52 Iranian postgraduate students' perceptions toward challenging 
academic writing. The results indicated that based on the Iranian students' perception, they would be able to write good academic writing quality both their dissertations and articles.

This study aims to investigate the effects of Texts-based Interactional Feedback (TIF) on a student's EFL writing with two research questions under investigated: 1). How is the student EFL writing result toward the TIF implementation? 2). what is the student's perception after the TIF implementation in EFL classroom?

\section{LITERATURE REVIEW}

\subsection{Previous Related Findings}

A study on descriptive writing performance in EFL context through dialogue journal writing has been investigated by Dabbagh (2017). In his study, 84 students were divided as both control and experiment group in the age of 17 to 22 years old students. The focus research in his study was the writing contents, organization, vocabulary, language use, and mechanics using quantitative analysis. The results indicated that there are three scoring focus that have significant differences in the post test, such as content, organization, and vocabulary and no significant achievement for language use, and mechanics. Therefore, this study is recommended for teachers to be practiced in the teaching writing activities for those who want to improve these three scoring frameworks, including content, organization, and vocabulary to earn a meaningful text.

Mehrpour (2017) also has investigated on the supervisory feedback efficiency among the 10 Iranian EFL Teachers' and 8 Supervisors' perception using 20-to-35 minutes of set discussion and interview. Based on the study, there is one important point which needs to be underlined and as a focus for effective supervisory feedback, that is by questioning on what makes the effective supervisory feedback. The results indicated some recommended adoption for EFL teachers and supervisors, including "creative approach, use above-the-utterance mitigation, meet the teachers' ZPD, be socioculturally sensitive, assess teachers' beliefs and attitudes and, last but not least, develop public relations skills" (p.32), and recommended the school to empower its supervisors to know more their supervisory responsibility in conducting effective critical feedback.

A study in academic writing using Written Corrective Feedback (WCF) Poorebrahim (2016) disposed more to the explicit and implicit students' corrective feedback. Her study in the EFL context compared both explicit feedback approach to seven students and implicit corrective feedback approach to other seven students with the age of 15 to 17 years old students. The test was essay writing with the focusing scoring on grammar, words choice, and spelling error which changes the meaning. The results showed that the accurate correction of grammatical errors was mostly completed by a group of "Indication-Location" approach (IL), while word and sentence changes are mostly applied by a group of "Indication" approach (p. 189). Then, the statistical evaluation stated that the accuracy didn't show significantly on 'indirect WCF" and the error occurrences in draft writing revision weren't considerably enough. So, her study stated that the more WCF, the more time 
consuming and the more assignments given are applied in the study, the more accuracy occur significantly. In short based on her study, intentional purposes need designed for more beneficial output, such as writing edition and revision tended more explicit feedback while knowledge improvement used implicit feedback (p.190).

The study on corrective feedback also had revealed that in particular context, mostly students in EFL classroom conducted feedback passively with their teachers, while in the other situations; students can indicate their anxiety to actively conducting feedback. The results show that because some students prefer direct corrective feedback, some considerable attention need to be implemented for confortable learning to achieve the students' writing improvements as the main goal, such as students' linguistic abilities, preference and interest, Zarifi (2017; p. 259).

Most studies stated in the previous above indicated that feedback approach in the teaching need design for more significantly improving the results. Although this study has similar in feedback case in EFL classroom, most content based study with this study is completely different in various fundamental based researches. First of all, this study bases on TIF meant that the interactional feedback between teacherresearcher and student based on the academic text composed by the student. This is a case study to a student programing thesis which was deeply analyzed using qualitative method. Then, the scoring framework in this study used linguistic features, Crosley (2014; p.189) involving lexical sophistication, syntactic complexity, and rhetorical structures.

\subsection{Framework of this study}

The theoretical framework of this study focused on the student's written texts by conducting interaction about her works. After that, the student corrected her own texts based on the results of our interactional feedback. The figure could be as the following:

\section{EFL Written Texts}

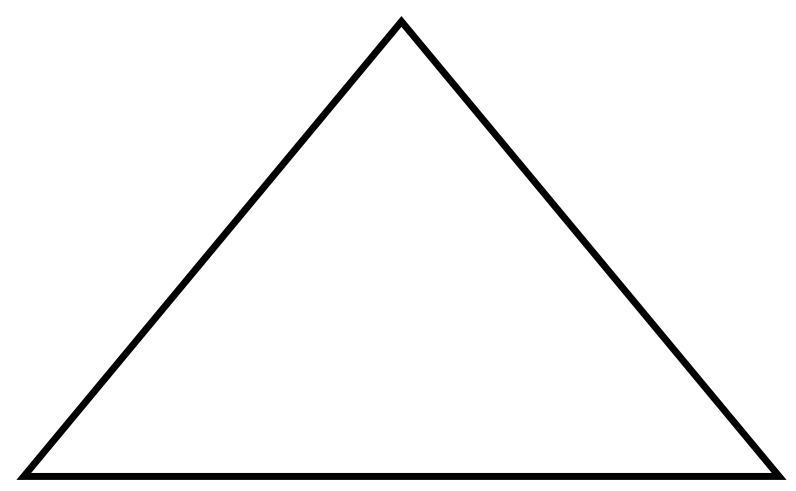

Teacher's interactional Student's correcting Texts feedback

Figure 1. The process of interactional feedback in student's EFL writing 


\section{RESEARCH METHOD}

This research is to answer two research questions, to prove with a scientific approach, and to develop an academic writing theory. This study uses qualitative method by which analyze the first student's writing thesis and the last one.

\subsection{Participants and Settings}

This is a case study in academic writing in the EFL context. An-eight-grade student programing research thesis who enrolled in English literature study program at Makassar Islamic University, Indonesia had participated in this research. The process implementing the TIF in the student' thesis writing was 4 times with notes, in the ranging time of 8-10 months period. The participant was 20 years old student, which English is as a foreign language, but English is her major study program. In this context, the writing is thesis writing which focused on after conducted proposal that are the findings, discussion, and conclusion. Furthermore, the thesis writing is the last and the biggest works in pursuing the bachelor degree in the university study.

\subsection{Instruments}

The instruments used in this study were student's thesis writings in the first time supervisory activity and the last paper and interview. The student's thesis writing meant that when first supervision was conducted or before applying the TIF approach and the last paper results were both analyzed, while the second and third meeting scoring were ignored. Then, the interview was carried out at the end of the series completed activities.

\subsection{Procedures}

After the participant had conducted a research and made a writing report, she consulted to the two supervisors. The supervisor brought home the paper for reading for understanding, giving signs for the text-based interactional feedback and copied it for primary data. The next day is the Text-based Interactional Feedback (TIF) implementation begun to be applied for the first time. The subject discussed in the supervision based on text which she wrote in her thesis, such as following some questions and giving some responds on "what do you mean the paragraph....., why do you write in this section...., why do you organize such this kind.

how do you get this data...., how do you put code..., etc". The length of supervisory time is ranging 30 to 40 minutes per meeting. After 4 times conducting supervision implementing TIF based, the last thesis writing was copied for the data in this study. The first and the fourth report writing were analyzed, while the second and the third meeting were ignored. The writing analysis only focused on the findings, discussions, and conclusion. In this study, the supervisor only focused on the interactional feedback of texts-based in the supervisory process and didn't determine or justify the correct or false writing.

After the primary data had been completed, the researcher conducted interview to the participant of this study for a secondary data. It aimed to know her perception toward this approach in her writing results. Therefore, the interview focused on: 1) 
writing development results, 2). the roles of TIF according to her, 3). and effective factors according to the participant.

\subsection{Scoring the Thesis Writing}

The text analysis in this study focused on the linguistic features involving lexical sophistication, syntactic complexity, and rhetorical structures, Crosley (2014; p.189). The lexical sophistication was considered as one of indicator in successful writing, because those indicated the writers' capability to write complex texts. Moreover, he argued that the longer texts were written by the one, the more successful the person linguistically. The data analyzed in this study were student's thesis writing in the first time supervision and the last time supervision or the fourth consultation. The data were marked using different stabile colors, i.e. a lexical sophistication using green color, the syntactic complexity marked by pink and the rhetorical structures by giving notes in the right papers.

\section{FINDINGS}

\subsection{Data Texts}

The student's written texts were investigated or analyzed based on its linguistic features, including its lexical sophistication, syntactic complexity, and rhetorical structure. The lexical sophistication referred to the vocabulary choices and grammatical use, whether the same vocabulary tended to recur in many times. Then, the syntactic complexity referred to the sentence formation which the longer sentences the participant wrote, as long as in the correct grammar and the clear meaning, the more linguistic intelligence the participant was. It tended to how the participant constructed the sentence to be, for example simple, compound, or complex sentences. Moreover, the rhetorical structure referred on how the texts were organized by following steps or pattern, such as applied by (Al Qahtani, 2006; Adnan, 2011; Hartley, 2008; Jalilifar, 2010; Jogthong, 2001) in analyzing the rhetorical structure in the research article introduction.

Table 1. The Results from the student's Finding Sections

\begin{tabular}{|c|c|}
\hline Paper before applying TIF & Paper after applying TIF \\
\hline \multicolumn{2}{|c|}{ Lexical sophistication } \\
\hline $\begin{array}{l}\text { The participant's writing showed some } \\
\text { lexical sophistication in her research thesis, } \\
\text { such as "the sentence ................... } \\
\text { means that a quick way to achieve the goals } \\
\text { and it describes as a springboard used by } \\
\text { some elements who demanded to imprison } \\
\text { Ahok in the case blasphemy Governor } \\
\text { Basuki 'Ahok' Tjahaja Purnama", Nurrahmi } \\
\text { (2017; pp. 25). Although it has a long } \\
\text { sentence, rarely or never occur the same } \\
\text { words. }\end{array}$ & $\begin{array}{l}\text { In the last paper, the texts also indicated that } \\
\text { almost all the sentences have the same } \\
\text { sentences, and some similarities with the } \\
\text { first paper. For example, the texts such as } \\
\text { found in the first paper, were also found in } \\
\text { the last paper. Therefore, in this stage, only } \\
\text { a few data proved that it has improvement. }\end{array}$ \\
\hline
\end{tabular}




\section{Syntactic complexity}

Most sentence constructions in the first paper have syntactic complexity, and only a few texts were written in simple form. For examples, the sentence such as "the words 'group' in question are GNPF MUI and FPI where the word 'group' is used as pronoun representing the two organizations", Nurrahmi (2017; pp. 26).

Rhetorical structures

The data analysis using the rhetorical structure in the first paper showed little complicated because the participant wrote and organize her data based on the opinion, not on the subjects being evaluated. For example, $1^{\text {st }}$ opinion tells about second opinion explains about.... Etc.
In this stage, syntactic complexity also was also in the participant' writing. What she wrote in the first paper also appeared in the last paper and there were only a few changes in syntactic complexity sentence.
In the rhetorical structures, many data showed changes, and these mostly happened in the research finding section. For example, the student wrote and organized her ideas based on the scoring frameworks, such as the data indicating metaphor showed "a particular number". Then, the personification data have proved "a particular number". The results revealed that the texts written in this rhetorical structure are more easily understood, so it may ease the readers getting the points stated. Furthermore, the writing using this rhetorical structure had 4 longer written text pages than the first paper.

The table 1 above showed that lexical sophistication rarely occurred in the texts, which also happened in the last paper. It indicated that there was no influence between the first and the last paper in the finding section. Then, the data also explained that syntactic complexity had been applied and found mostly in each paragraph in the finding section and it didn't tell us any changes. So, although the syntactic complexity had been written in both first paper and the last paper, there was no improvement found in this section. On the other hands, the rhetorical structure was totally different between first paper and the last paper in the finding section. It was happened by showing that the first paper was written by knowledge of paper reviewed while the last paper was focused on the scoring framework. The results revealed that the last paper is more understandable and more acceptable.

Table 2. The Results from the student's Discussion Sections

\begin{tabular}{|c|c|}
\hline Paper before applying TIF & Paper after applying TIF \\
\hline \multicolumn{2}{|c|}{ Lexical sophistication } \\
\hline $\begin{array}{l}\text { In the discussion section, only a few words } \\
\text { or phrases indicated lexical sophistication } \\
\text { which the texts were approximately } 11 \text { pages } \\
\text { length and mostly the vocabularies used in } \\
\text { the writing were common. There were lack } \\
\text { quotations in this section. }\end{array}$ & $\begin{array}{l}\text { The last paper showed indifferent change } \\
\text { with the first paper and what the texts } \\
\text { written in the first paper were the same as } \\
\text { the last paper. }\end{array}$ \\
\hline
\end{tabular}




\section{Syntactic complexity}

Syntactic complexity data showed various complex sentences which majority involved in all the writing, except only a few numbers of sentences. For example, the participants wrote "metaphor is also an implicit comparison and the use of words that are not the real meaning, but rather as painting based on equation or comparisons".

Rhetorical structures

The rhetorical structure used in the first paper of discussion section revealed that the texts relatively easily comprehended because its structures based on the scoring framework as organizing texts. For examples, the first and second paragraph discussed metaphor data supported by a theory, the third data explained personification, etc. On the other hands, the discussion didn't deliver her readers to review the research questions which would be the most focus of discussion.

The data in the discussion section revealed that there was no significant difference in all linguistic features, including lexical sophistication, syntactic complexity, and rhetorical structure, because most texts written in the first and the last paper indicated similar in terms of the scoring frameworks. On the other hands, both papers in the first and the last one indicated having lexical sophistication, syntactic complexity, and good rhetorical structures. In addition, the texts written in the last paper discussion section have longer than in the first paper. It was the only change happened in this section.

Table 3. The Results in the Conclusion and Suggestion Sections

\begin{tabular}{|l|l|}
\hline \multicolumn{1}{|c|}{ Paper before applying TIF } & \multicolumn{1}{c|}{ Paper after applying TIF } \\
\hline $\begin{array}{l}\text { In the conclusion section, although the lexical sophistication had some } \\
\text { sophisticated texts, syntactic complexity appeared in several paragraphs, and the } \\
\text { rhetorical structure have nice comprehension, all the texts didn't have any changes } \\
\text { with the first paper. }\end{array}$ \\
\hline
\end{tabular}

In the conclusion section of those first and last papers indicated that lexical sophistication, syntactic complexity, and rhetorical structure also happened, but there was no far difference between the first and the last one. Therefore, this section also has similarity with showed in the table 2 but it has not balanced with the table 1 . 


\subsection{Data Interview}

In this stage, the writer-supervisor involved interview as one of data collection in which this aimed to know the participant's perception toward her writing development results, the roles of TIF according to her perception, and the effectiveness of this TIF such the participant perceived.

As the interview with the participant, her writing has developed in some aspects, for examples when writing a research report, firstly he got difficulties in the beginning, where she should be started from, how to organize, and what should be suitable for. After the supervisory activities through Text-based Interactional Feedback (TIF), she may have been more easily on how to organize the research reports. She felt rather satisfied with this program when she was interviewed because she has an experience-knowledge which has been applied in the thesis writing. This was the first time implemented in her life, so she felt having more improvement compared in the previously done. She though that this strategy has an adequate improvement in particular knowledge and skills, because it can help her academic writing for better text rhetorical structures. Therefore, it may have effectiveness in academic writing developments, according to her.

\section{DISCUSSION}

This study aimed to prove the research by data on the questions of how the student academic writing results toward the TIF implementation and to develop student's EFL writing theory more particularly in conjunction with the scoring frameworks such as referring to the lexical sophistication, syntactic complexity, and rhetorical structure, Crosley (2014; p.189). After that, this study is also to investigate and report the student's perception after the TIF implementation. These two aims are becoming the purposes of this study.

In relation to the aims of this study and to respond the first research question, that this has investigated the development of linguistic features. The most developed linguistic feature is the rhetorical structure which mostly changed in the finding section of this study. The results indicated that the texts written by the participant had much more easily understood than in the first one, while in other sections there was no indication improvement because they are mostly similar. Therefore, the rhetorical structures have implied significant improvements and this study about rhetorical structure has been familiar in various texts, for example, in the research introduction (Al Qahtani, 2006; Adnan, 2011; Hartley, 2008; Jalilifar, 2010; Jogthong, 2001), and in the various academic articles (Swales \& Feak; 2004). Moreover, the written texts whether were accepted and published in the reputable journal could be depending on this rhetorical structure. Rhetorical structure is one of difficult consideration in the text analysis which need deeply investigated, because different interpreters may have variable results. Iruskieta, Cunha, \& Taboada (2015), for example, had investigated among three "annotators" who disposely interpreted the same texts and language differently which it was possibly affected by different knowledge and skill background (p. 301), or it may possibly influenced by the cultural academic backgrounds. Rhetorical structure is becoming more popular since the study is in conjunction with writing publication. 
Another part of linguistic features which is one of the focuses in this study is lexical sophistication. The data showed that there were some lexical varieties found in the texts both in the first and the last paper, and this investigation didn't show improvements in the last paper because most texts were not different with the first paper before conducted the TIF. Therefore, because some texts have contained lexical sophistication, the participant may be referred as in the intermediate level of English, particularly in the lexical sophistication. It was showed that rarely the participant used the same words in the same contexts. Although the text written had long and complex sentences, she tended to use other or in different vocabularies. This is similar to Crosley research results $(2014 ;$ p.189) that the more lexical sophisticated text the one produced, the more proficient the one in the syntactic level is. Lexical sophistication involved reliability in vocabulary choices and correct grammar in the texts, while grammatical errors are commonly happened for EFL learners, for examples Indonesian learners, which then followed by punctuation and spelling, Hasan \& Marzuki (2017: p.378). Then to have much more vocabulary achievement, many strategies should be applied, for example reading text continuously and making the review or summary, reading by taking a note, or other strategies which are probably appropriate in your case such as investigated by Iswandari at.al.(2017). In addition, because both vocabulary choice and language grammar have important roles to achieve the lexical sophisticated writing, reading academic publication and analyzing academic texts may help for better understanding and improve our lexical writing sophistically.

The last linguistic feature of this study, but not least, was investigation to the syntactic complexity which revealed that there was no different between first paper and the last paper. What the participant wrote in the first paper in relation to the syntactic complexity was not different from the others. In the other hand, the most texts produced by the participant had syntactic complexity for both first and the last papers. This was in connection with the sentences which are mostly in the complex form by using the various connectors. Although there was not any improvement in the syntactic complexity level, this study indicated that the participant has high level on syntactic complexity. It is different with the Noriega' research findings which connectors were mostly used inappropriately and the students tended to avoid using them, because the participant didn't recognize how to use them $(2016 ;$ p.198). Therefore, the participant in this study could be said as intermediate level of linguistics, more specifically in the syntactic complexity comprehension. However, the syntactic complexity tended to avoided by mostly students in the sentence writing, because it is one big obstacle in language learning. A study on syntactic complexity had been revealed that "individuals with Down syndrome" always made their sentences simply and reduced some important words and meanings. "This could be a result of these individuals' limitation in auditory memory. If there is a critical period for syntactic learning based on age, linguistic complexity, other factors, or some combination, these individuals have not passed it" (Thordardottir, at al. 2002: pp. 181).

Regarding to the participant' perception to the TIF implementation, when the data were collected using interview, she tended to argue in the positive face that 
revealed this TIF is ably used in the teaching and supervising academic writing strategy and her attitudes indicated the satisfaction toward the implementation. This study may agree with the stating result from Poorebrahim (2016) who revealed that the more time consuming and the more assignments given are applied in the study, the more accuracy occur significantly. In other hands, this study must be more highly directed that the effectiveness should be in the 'concepts' for better results as the interactional purposes for more effective feedback such as Mehrpour' study (2017). In addition, this data has been collected from the participant directly to know the students' perception to avoid misconception which may frequently result imbalanced perception. For example referring to Meltzer at.al. (1998) who investigated the students' perception and their teachers' perception toward the students' capability resulted that "students with learning disabilities frequently perceive themselves as capable and effective and often rate themselves as academically stronger than the teachers judge the to be", (p.437). Therefore, perception can't be extemporaneously applied and it needs the real investigation to prove the real fact and this study has shown the convincing data.

On the other hands in connection with the learning writing achievement, teaching-learning commitment for both teacher and learner is becoming one of the important roles considered in the EFL writing class. A socio cognitivetransformative study has proved that "the success of such an approach greatly depends on the commitment and persistence of both the teachers and learners to break the barrier of complacency and individualistic approach to acquiring and using writing skills", (Barrot, 2015, p.121).

\section{CONCLUSION}

This study indicates that the TIF implementation can be applied in academic writing. The analysis showed that it was more effective implemented in the rhetorical structure focus on the academic writing, which it tended to the easier text comprehension. On the other hands, the analysis based on the lexical sophistication and syntactic complexity didn't showed the changes significantly and effectively, but the participant's comprehension in this level has been intermediate level which can be showed by the most written texts in this study. Moreover, the participant's perception indicated that this TIF application can help her in the academic writing to be much better than before this study.

\section{REFERENCES}

Adnan, Z. (2011). Ideal-Problem-Solution (IPS) Model; Discourse Model of Research Article Introductions (RAIs) in Education. Pp.71-103.

Al-Qahtani, A. (2006). A Contrastive Rhetoric Study of Arabic and English Research Article Introductions. Submitted to the Oklahoma State University.

Barrot, Jessie. (2015). A Sociocognitive-transformative approach to teaching writing. Indonesian Journal of Applied Linguistics, Vol. 4 No. 2, pp. 113-122 
Bezemer, Jeff \& Kress Gunther. (2008). Writing in Multimodal Texts: A Social Semiotic Account of Designs for Learning. Written Communication. Published by SAGE, Volume 25 Number 2. Pp. 166- 195

Crosley, Scott A., Roscoe, Rod., \& McNamara, Danielle S. (2014). What Is Successful Writing? An Investigation Into the Multiple Ways Writers Can Write Successful Essays. Written Communication journal. SAGE Publication. p. $184-214$

Dabbagh. Ali. (2017). The Effect of Dialogue Journal Writing on EFL Learners' Descriptive Writing Performance: A Quantitative Study. International Journal of Applied Linguistics \& English Literature. Vol. 6 No. 3; pp. 71-80, doi:10.7575/aiac.ijalel.v.6n.3p.71

Dyson, Anne Haas. (2013), The Case of the Missing Childhoods: Methodological Notes for Composing Children in Writing Studies. Written Communication, SAGE Publications 30(4) pp. 399-427

Gurbangeldiyewna. Atayewa. Merjen \& Hermayawati. (2017). The Effectiveness Of English Interactive Media In Teaching Writing (An Experimental Study Conducted For Eleventh Graders In Sma N1 Sedayu, Bantul Yogyakarta). Journal of English Language and Education. Vol 3. No. 1, pp. 17-28

Hartley, J. (2008). Academic Writing \& Publishing. A Practical Handbooks. NY: Routledge

Hasan. Jismulatif. \& Marzuki. M. (2017). An Analysis of Students' Ability in Writing at Riau University Pekanbaru- Indonesia. Theory and Practice in Language Studies. Vol. 7., No. 5. pp. 380-388. DOI: http://dx.doi.org/10.17507/tpls.0705.08

Hayes. John R. (2012). Modeling and Remodeling Writing. Written Communication. SAGE Publications 29(3) pp. 369-388

Hua. Zhe; Wei. Li; Seedhouse. Paul; Cook.Vivian. (2007). Introduction to Language Learning and Teaching as Social Inter-Action. Antony Rowe Ltd, Chippenham and Eastbourne. Pp 1-8

Iruskieta. M., Cunha. I.D., \& Taboada. M. (2015). A Qualitative Comparison Method for Rhetorical Structures: Identifying Different Discourse Structures in Multilingual Corpora. Lang Resources \& Evaluation. pp. 49:263-309, DOI: 10.1007/s10579-014-9271-6

Iswandari. D.C., Prayogo. J.A., \& Cahyono. B.Y. (2017). Effects Environmental Problem-based Learning on the Indonesian EFL learners Environment-related Vocabulary Mastery and Writing Ability. Theory and Practice in Language Studies. Vol.7,No.8, pp. 608-616, http://dx.doi.org/10.17507/tpls.0708.02

Jalilifar, A. (2010). Research Article Introductions: Sub-disciplinary Variations in Applied Linguistics. The Journal of Teaching Language Skills, 2(2), Page 3055

Jogthong, C. (2001). Research Article Introductions in Thai: Genre Analysis of Academic Writing. Research for doctoral program. Morgontown, Virginia.

Kotamjani. Sedigheh Shakib. (2017). Perceptions of Challenges in Writing Academically: Iranian Postgraduate Students' Perspectives. International 
Journal of Applied Linguistics \& English Literature. Vol. 6 No. 4; pp 1-4, doi:10.7575/aiac.ijalel.v.6n.4p.1

Kuure. L., Saarenkunnas. M., and Taalas. P. (1998). Negotiating a New Culture of Doing Learning? A Study of Interaction in a Web Learning Environment with Special Focus on Teacher Approaches. University of Oulu, University of Jyväskylä.

McKay. S. L. (2002). Teaching English as an International Language. Rethinking Goals and Perspective. Oxford University Press.

Mehrpour. Saeed. (2017). Supervisory Feedback Efficiency: Developing a Framework Based on Iranian EFL Teachers' and Supervisors' Perceptions. International Journal of Applied Linguistics \& English Literature, Vol. 6 No. 3; pp. 24-33, doi:10.7575/aiac.ijalel.v.6n.3p.24

Meltzer, Lynn;Roditi, Bethany;Houser, Robert F, Jr;Perlman, Melissa. (1998). Perceptions of academic strategies and competence in students with learning disabilities. Journal of Learning Disabilities; 31, 5; Arts \& Humanities Database. pp. 437-451

Noriega. Heydy Selene Robles. (2016). Mobile Learning to Improve Writing in ESL Teaching. TEFLIN journal. Pp. 182-202, DOI: http://dx.doi.org/10.15639/teflinjournal.v27i1/182-202

Nurrahmi. (2017). The Analysis of Figurative Language Used in Opinion Section of The Jakarta Post Online Newspaper in Presenting Religious Defamation Issue. Unpublished thesis at Makassar Islamic University.

Okasha. Mohamed A. \& Hamdi. Sami A. (2014). Using Strategic Writing Techniques for Promoting EFL Writing Skills and Attitudes. Journal of Language Teaching and Research, Vol. 5, No. 3, pp. 674-681, doi:10.4304/jltr.5.3.674-681

Poorebrahim. Fatemeh. (2016). Indirect Written Corrective Feedback, Revision, and Learning. Indonesian Journal of Applied Linguistics, Vol.6 no.2 pp. 184-192, doi:dx.doi.org/10.17509/ijal.v6i2.4843

Rodliyah. Rojab Siti. (2016). Using a Facebook Closed Group to Improve EFL Students' Writing. TEFLIN journal. Pp. 82-100, doi: http://dx.doi.org/10.15639/teflinjournal.v27i1/82-100

Seedhouse, Paul. (2007). Interaction and Constructs. Language Learning and Teaching as Social Inter-Action. Antony Rowe Ltd, Chippenham and Eastbourne. Pp. 9-21

Swales, J. M. \& Feak, C. B. (2004). Academic writing for graduate students. Ann Arbor, MI: University of Michigan Press.

Tahmasebi. Reza \& Khodabakhshzadeh. Hossein. (2017). Enhancing Writing Ability and Self-regulation through Teacher-led Collaborative Modeling. International Journal of Applied Linguistics \& English Literature. Vol. 6 No. 2; pp. 239-248, doi:10.7575/aiac.ijalel. v.6n.2p.239

Thorne. Barrie. (2001). Gender and interaction: Widening the conceptual scope. (Gender in Interaction: Perspectives on femininity and masculinity in ethnography and discourse). Edited by Bettina Baron, Helga Kotthoff. Published by John Benjamins Company 
Thordardottir, Elin T., Chapman, Robin S., Wagner, Laura. (2002). Complex sentence production by adolescents with Down syndrome. Applied Psycholinguistics 23, pp. 163-183. DOI:10.1017.S0142716402002011

Zarifi. Abdolvahed. (2017). Iranian EFL Learners' Reaction to Teacher's Written Corrective Feedback. International Journal of Applied Linguistics \& English Literature. Vol. 6 No. 3 pp. 354-361, doi:10.7575/aiac.ijalel.v.6n.3p.254 